\title{
Neoadjuvant chemotherapy is associated with a high rate of perioperative blood transfusion at the time of interval cytoreductive surgery
}

Kevin W McCool ${ }^{1,6}$, Emmanuel Sampene ${ }^{2}$, Brock Polnaszek ${ }^{4}$, Joseph Connor ${ }^{3}$, Erin E Medlin ${ }^{1,5}$ and Lisa Barroilhet ${ }^{1 *}$ (D)

\begin{abstract}
Background: The oncologic safety of allogeneic blood transfusion in ovarian cancer patients is unknow. We sought to determine the prevalence and oncologic safety of perioperative allogeneic blood transfusion during interval cytoreduction surgery among women receiving neoadjuvant chemotherapy for ovarian cancer.

Methods: We utilized retrospective chart review to identify a cohort of patients undergoing interval cytoreduction at a large academic tertiary referral center. We compared outcomes in patients who were exposed to perioperative blood transfusion compared with patients who were not exposed. Our primary endpoint was progression free survival; our secondary endpoint was overall survival. Baseline clinical characteristics were collected for patients in each group.

Results: Sixty-six women were included in the final cohort of women undergoing interval cytoreductive surgery after NACT. A total of 51 women (77\%) were exposed to allogeneic perioperative pRBC transfusion. Fifteen women (23\%) were not exposed to transfusion. The baseline characteristics were generally well matched. Women who were not exposed to a perioperative blood transfusion were more likely to have a normalized CA125 prior to undergoing cytoreductive surgery. Preoperative hemoglobin concentration was lower in the transfusion group (10.5 g/dLvs $11.5 \mathrm{~g} /$ $\mathrm{dL}, p<0.009$ ). Perioperative transfusion was not associated with a significant difference in progression free survival (PFS $=7.6$ months for transfused, 9.4 months for not transfused; log-rank test $p=0.4617$ ). Similarly, there was no observed difference between groups for overall survival (OS = 23.6 months for transfused, 22.5 months for not transfused; log-rank test $p=0.1723$ ).

Conclusions: Women undergoing neoadjuvant chemotherapy for ovarian cancer are at high risk of exposure to blood transfusion at the time of interval cytoreductive surgery. Future studies will continue to evaluate the safety and impact of transfusion on ovarian cancer survival in this at risk population.
\end{abstract}

Keywords: Ovarian cancer, neoadjuvant, interval cytoreduction, blood transfusion

\footnotetext{
* Correspondence: barroilhet@wisc.edu

${ }^{1}$ Division of Gynecologic Oncology, Department of Obstetrics and Gynecology,

University of Wisconsin, 600 Highland Ave, Madison, WI 53792, USA

Full list of author information is available at the end of the article
}

(c) The Author(s). 2018 Open Access This article is distributed under the terms of the Creative Commons Attribution 4.0 International License (http://creativecommons.org/licenses/by/4.0/), which permits unrestricted use, distribution, and reproduction in any medium, provided you give appropriate credit to the original author(s) and the source, provide a link to the Creative Commons license, and indicate if changes were made. The Creative Commons Public Domain Dedication waiver (http://creativecommons.org/publicdomain/zero/1.0/) applies to the data made available in this article, unless otherwise stated. 


\section{Background}

Blood transfusion has been scrutinized in intensive care and trauma settings, as it is consistently associated with worse outcomes [1, 2]. In cancer patients, perioperative blood transfusions have been shown to worsen survival in colorectal, breast and other malignancies [3-7]. These findings have been inconsistently replicated in patients with ovarian cancer $[8,9]$ but limited research in this area has been published. The treatment paradigm for patients with advanced ovarian cancer has shifted in the last eight years. The use of neoadjuvant chemotherapy (NACT) as an alternative to upfront debulking surgery has gained widespread acceptance after two randomized controlled studies showed equivalent survival between these treatment paradigms $[10,11]$. We reasoned that patients undergoing going interval cytoreductive surgery after NACT would be uniquely at risk for perioperative anemia secondary to myelosuppressive chemotherapy. Consequently we anticipated a high prevalence of perioperative blood transfusion in this growing patient population. However, the impact of perioperative blood transfusion on progression-free survival (PFS) and overall survival (OS) remains an unanswered question. We identified a retrospective cohort of patients with ovarian cancer undergoing interval cytoreduction after NACT at our institution over a 3 year period to determine the prevalence of perioperative blood transfusion and explore the impact on OS and PFS.

\section{Methods}

We utilized Electronic Health Records (EHR) from women undergoing treatment of ovarian cancer at the University of Wisconsin Hospital from January 12010 to December 31 2013. We selected our data collection window to coincide with the increased uptake of NACT after the publication of EORTC 55971 trial in 2010. A search of patient data from prior to 2010 showed an overall low rate of NACT at our institution. We chose to terminate data collection in 2013 to provide opportunity for maturation of survival data. We utilized ICD9 code 183 and CPT codes 58943 and 58950-58956 to identify all women undergoing surgical treatment for ovarian cancer. We then manually interrogated records to identify women who had previously received chemotherapy prior to surgical management. There are no well-defined criteria for peri-operative blood transfusion described in the literature. We chose to define the exposure of interest, perioperative allogeneic blood transfusion, as any women who received allogeneic packed red blood cells during their index hospitalization for interval cytoreduction surgery. We surmised that there is great variability in the timing and utilization of blood products depending on patient factors and provider preferences. As a result, we chose this broad definition to be maximally inclusive of exposures surrounding interval surgery. The primary outcome of interest was progression-free survival and the secondary outcome was OS, calculated as the interval from surgery until recurrence or death, respectively. Recurrence was defined as any clinically suspected recurrence by imaging, exam or biochemical findings. Demographic data including age and BMI were obtained, as well as clinical data including pre-treatment CA125, preoperative CA125, preoperative clinical stage, chemotherapy regimen, optimal cytoreduction status, final surgical stage, preoperative hemoglobin and number of units of packed red blood cells transfused. Women lost to follow up were censored from survival analysis. For the primary analysis of PFS and the secondary endpoint of OS, the difference in treatment arms was assessed using Kaplan-Meier (KM) methods and the log-rank test. Median, ranges, the proportion of subjects who are progression free in this cohort, hazard ratios and corresponding 95\% confidence intervals (as calculated using a Cox proportional hazards regression model) are presented. In addition, differences in the frequency distributions of baseline covariates by transfusion type were compared via Chi-square or Fisher's exact test test for categorical variables and a t-test for continuous variables. Data analysis was performed using the SAS v9.4 software. The study protocol was submitted to the UW-Madison Institutional Review Board and granted exemption status.

\section{Results}

We identified 273 women who received surgical treatment of ovarian cancer at the University of Wisconsin between 2010 and 2013. A total of 70 (25\%) women underwent NACT prior to surgical cytoreduction, as compared to 203 (75\%) women undergoing primary cytoreduction surgery. Four women undergoing NACT were excluded in our final analysis; three had primary uterine cancer and one had primary appendiceal carcinoma. Sixty-six women were included in the final cohort of women who undergoing interval cytoreductive surgery after NACT (Fig. 1). The mean age of women included in the study was 69 years old, with a range from 33 to 87 . The mean BMI in our cohort was $28 \mathrm{~kg} / \mathrm{m} 2$, with a range from 18 to 49 . An overwhelming majority of patients in the cohort had high grade papillary serous histology (91\%). Other histologies included low grade serous (3\%), clear cell $(3 \%)$, mucinous (1.5\%), and endometrioid (1.5\%). The mean pre-treatment CA125 for the overall cohort was 2818 units $/ \mathrm{mL}$, with a range from 15 to 30,536 units $/ \mathrm{mL}$. The mean pre-surgery CA125 (last documented value prior to date of surgery) was 259 units $/ \mathrm{mL}$, with a range from 3 to 6190 units $/ \mathrm{mL}$. Of the 66 women included in the final cohort, 22 patients (33\%) had a normal CA125 prior to surgery. Given that residual tumor burden is the 


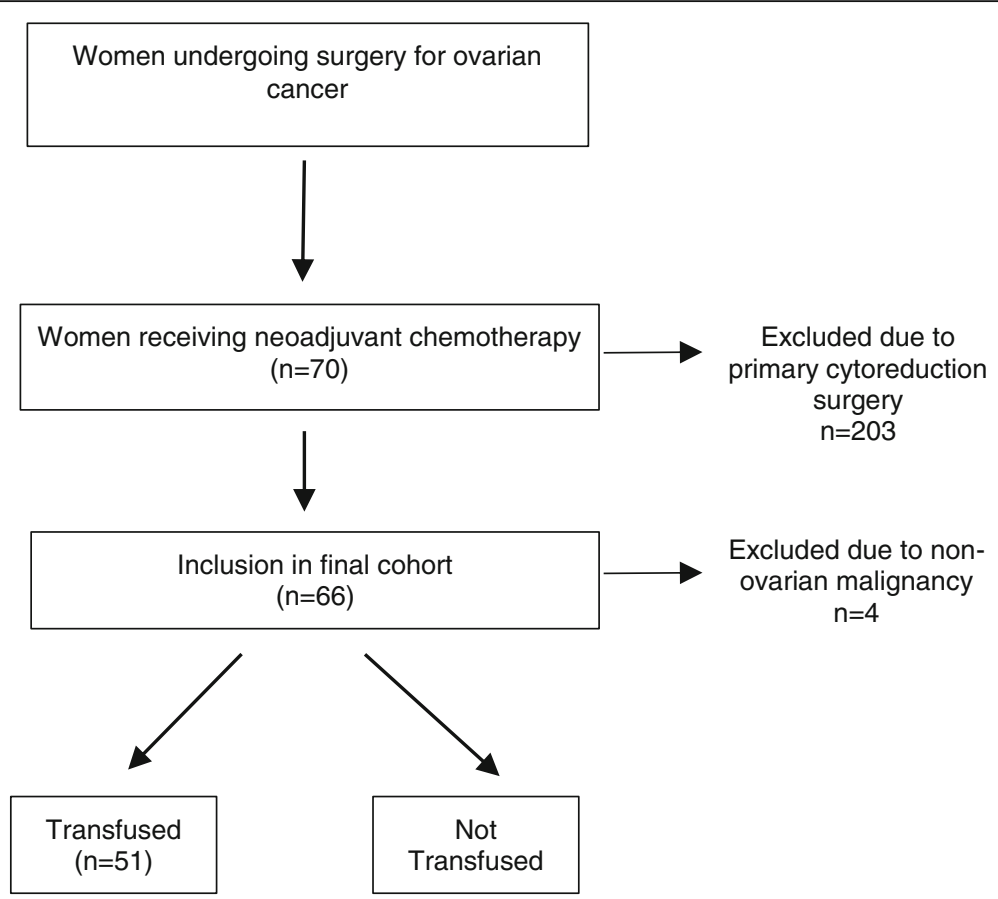

Fig. 1 Study population: women treated for ovarian cancer at University of Wisconsin between 2010 and 2013

most important surgical variable for ovarian cancer survival, we gathered this data on surgical outcome for the entire cohort. Optimal debulking status was known for all patients. Seventeen out of $66(26 \%)$ had no visible disease after surgery. Twelve out of $66(18 \%)$ had cytoreduction to $1-5 \mathrm{~mm}$ of visible disease. Twenty-nine of 66 (44\%) of patients had cytoreduction to less than or equal to $1 \mathrm{~cm}$ of visible disease. Eight of 66 (12\%) had a suboptimal cytoreduction. Operative blood loss was also known for all patients, with a mean intraoperative blood loss of $539 \mathrm{~mL}$ (range 100-2000 mL). Among all patients, the mean preoperative hemoglobin concentration was $10.6 \mathrm{~g} / \mathrm{dL}$.

The majority of our patients received a platinum-containing doublet delivered every 3 weeks prior to surgery. Fifty-five out of 66 (83\%) patients received neoadjuvant carboplatin and paclitaxel. Six out of 66 (9\%) received carboplatin, paclitaxel, bevacizumab prior to surgery. Five out of $66(8 \%)$ of patients received NACT with some other chemotherapy regimen (four with carboplatin/taxotere, one with carboplatin/gemcitabine). Four women received paclitaxel on a weekly (i.e. dose-dense) schedule. The majority of women in our cohort received 3 cycles of neoadjuvant chemotherapy (66\%). Forty-seven patients (71\%) had clinical stage III disease at the beginning of treatment, with 17 (26\%) patients having clinical stage IV disease. One patient had stage I disease; this patient presented to our facility with biopsy-proven clear cell cancer and extensive pulmonary emboli. She was managed medically with anticoagulation and neoadjuvant carboplatin-paclitaxel. Final surgical staging confirmed unilateral ovarian disease without contralateral ovarian involvement; given her preoperative biopsy she was managed as stage Ic. The median time to progression among the entire cohort was 7.7 months (range 0-53 months). The median time to death (overall survival) was 22.5 months (range 1 to 62.3 months. At the conclusion of the study, 19 patients were alive, and 45 were deceased. Two patients were lost to follow up without survival data available. Four women were in complete remission at the conclusion of the study.

The baseline characteristics of women in the transfusion and non-transfusion groups are shown in Table 1. A total of 51 women $(77 \%)$ were exposed to allogeneic perioperative pRBC transfusion. Fifteen women (23\%) were not exposed to transfusion. The mean number of units of packed red blood cells transfused was 2.98 units. The baseline characteristics were generally well-matched. There was no observed relationship between the number of preoperative chemotherapy cycles and the likelihood of exposure to blood transfusion. Women who were not exposed to a perioperative blood transfusion were more likely to have a normalized CA125 prior to undergoing cytoreductive surgery. (CA125 $<35$ units $/ \mathrm{mL}, \mathrm{p}=0.005$ ). Preoperative hemoglobin concentration was observed to be lower in the group exposed to blood transfusion $(10.5 \mathrm{~g} / \mathrm{dL}$ vs $11.5 \mathrm{~g} / \mathrm{dL}, p<0.009)$, and also observed to have a higher mean operative blood loss (613.7 $\mathrm{mL}$ vs $283.3 \mathrm{~mL}, p=0.004)$. The results of Kaplan-Meier analysis of our primary and secondary outcomes of interest are shown in Figs. 2 and 3. Perioperative transfusion was not associated with a significant difference in progression free 
Table 1 Baseline characteristics

\begin{tabular}{|c|c|c|c|}
\hline Variable & $\begin{array}{l}\text { Perioperative Transfusion: Yes }(\mathrm{N}=51) \\
\text { Mean (SD) }\end{array}$ & $\begin{array}{l}\text { Perioperative Transfusion: No }(\mathrm{N}=15) \\
\text { Mean (SD) }\end{array}$ & $P$-value \\
\hline Age & $69.0(11.46)$ & $71.1(9.60)$ & 0.5278 \\
\hline $\mathrm{BMl}$ & $28.0(7.31)$ & 26.7 (5.68) & 0.5183 \\
\hline \multicolumn{4}{|l|}{ Histology: } \\
\hline High grade pap serous & 46 & 14 & \multirow[t]{5}{*}{0.299} \\
\hline Low grade & 2 & 0 & \\
\hline Mucinous & 1 & 0 & \\
\hline Clear cell & 2 & 0 & \\
\hline Endometrioid & 0 & 1 & \\
\hline Pre-treatment CA125 & 3013.4 (5833.6) & $2156.9(2897.4)$ & 0.5863 \\
\hline Pre-operative CA125 & 198.8 (401.6) & $462.8(1585.2)$ & 0.2822 \\
\hline \multicolumn{4}{|l|}{ Normal Pre-op: } \\
\hline Yes & 11 & 9 & \multirow[t]{2}{*}{0.005} \\
\hline No & 39 & 6 & \\
\hline Delta CA125 & $2867.5(5702.6)$ & $1694.2(1592.9)$ & 0.4361 \\
\hline \multicolumn{4}{|l|}{ Pre-op Clinical Stage: } \\
\hline Stage 3 & 36 & 11 & \multirow[t]{2}{*}{0.992} \\
\hline Stage 4 & 13 & 4 & \\
\hline \multicolumn{3}{|l|}{ Pre-op Chemo: } & \multirow[t]{4}{*}{0.907} \\
\hline Carboplatin/Paclitaxel & 41 & 13 & \\
\hline Carbo/taxol/bevacizumab & 5 & 1 & \\
\hline Other & 4 & 1 & \\
\hline \multicolumn{3}{|l|}{ Dose-dense Taxol: } & \multirow[t]{3}{*}{0.258} \\
\hline Yes & 4 & 0 & \\
\hline No & 46 & 15 & \\
\hline \multicolumn{3}{|l|}{ Pre-op Chemotherapy cycle \# } & \multirow[t]{3}{*}{0.21} \\
\hline 3 or less & 37 & 8 & \\
\hline$<3$ & 14 & 7 & \\
\hline \multicolumn{3}{|l|}{ Optimal Cytoreduction: } & \multirow[t]{5}{*}{0.812} \\
\hline No visible & $12(23.5 \%)$ & $5(33.3 \%)$ & \\
\hline $1-5 \mathrm{~mm}$ & $9(17.6 \%)$ & $3(20 \%)$ & \\
\hline$\leq 1 \mathrm{~cm}$ & $22(43.1 \%)$ & $6(40 \%)$ & \\
\hline Suboptimal & $7(13.7 \%)$ & $1(6.7 \%)$ & \\
\hline \multicolumn{3}{|l|}{ Final Stage: } & \multirow[t]{5}{*}{0.646} \\
\hline IC & 1 & & \\
\hline$\| \mathrm{ll}$ & 38 & 10 & \\
\hline IVa & 8 & 4 & \\
\hline $\mathrm{IVb}$ & 4 & 1 & \\
\hline Pre-op HgB (g/dL) & $10.5(0.16)$ & $11.5(0.44)$ & 0.0091 \\
\hline Operative blood loss (mL) & $613.7(421)$ & $283.3(144.7)$ & 0.004 \\
\hline \multicolumn{4}{|l|}{ Number of Units Transfused } \\
\hline zero units & 0 & 15 & \\
\hline $1-3$ units & 36 & 0 & \\
\hline 4-7 units & 15 & 0 & \\
\hline
\end{tabular}


Table 1 Baseline characteristics (Continued)

\begin{tabular}{llll}
\hline Variable & $\begin{array}{l}\text { Perioperative Transfusion: Yes (N=51) } \\
\text { Mean (SD) }\end{array}$ & $\begin{array}{l}\text { Perioperative Transfusion: No (N=15) } \\
\text { Mean (SD) }\end{array}$ & $\begin{array}{c}P \text {-value } \\
\text { Days to death }\end{array}$ \\
Alive: & $662.9(65.7)$ & $865.8(177.6)$ & 0.1959 \\
Yes & 14 & 4 & 0.918 \\
No & 35 & 10 & \\
\hline
\end{tabular}

Median time to death was compared between patients who received perioperative blood transfusion (red line) versus those who did not (blue line). $\mathrm{OS}=23.6$ months for transfusion group; $\mathrm{OS}=22.5$ months for no transfusion group. Data were analyzed using the log-rank test

survival. Among women exposed to transfusion a median PFS of 7.6 months was observed, as compared to a median PFS of 9.4 months among women not exposed to transfusion (log-rank test $p=0.4617$ ). Similarly, there was no observed difference between groups for overall survival (23.6 months in transfused group, 22.5 months in not transfused group; log-rank test $p=0.1723$ ). We hypothesized that an inverse dose relationship might exist between the number of units transfused and survival. Using a Cox proportional hazards model, we found no significant association between number of units transfused and $\mathrm{OS}(\mathrm{HR}=1.06, \mathrm{CI}$ : 0.92-1.23) nor PFS (HR=1.14, CI: 0.87-1.50). Previous studies have demonstrated a pre-surgery normal CA125 as a positive prognostic variable. In our cohort a normal CA125 trended towards an observed increase in PFS, however there was no statistical difference in OS.

\section{Discussion}

Collectively, our experience from a single academic tertiary referral institution demonstrates a high utilization of perioperative $\mathrm{pRBC}$ transfusion at the time of surgery among women undergoing NACT for ovarian cancer.
To our knowledge, this is the first study to report the prevalence of blood transfusion among women undergoing NACT for ovarian cancer in North America. Specifically, our cohort was collected over a time interval during which an increasing number of women are being treated with primary chemotherapy and interval cytoreduction surgery. Patients receiving blood product transfusion face risks including infectious, allergic reactions, non-allergic immune reactions, and volume overload. Data from other patient populations suggests that allogeneic blood product transfusion may be associated with poorer oncologic outcomes [3-7]. This has been demonstrated in advanced ovarian cancer patients undergoing primary cytoreduction surgery for stage III disease where transfusion was associated with a shortened median time to progression or survival of 6 months and 22 months, respectively [8]. Our cohort specifically identified women undergoing surgery after NACT for ovarian cancer because we hypothesized that this patient population is at increased risk of chronic anemia secondary to bone marrow suppression from carboplatin and paclitaxel. Interestingly, we observed no relationship between

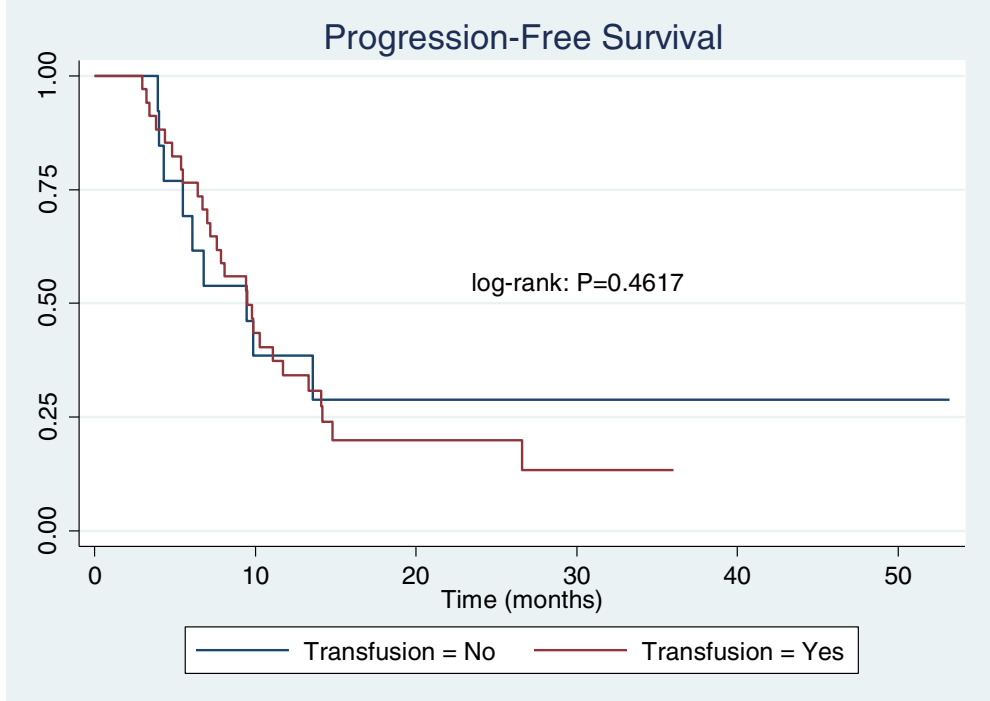

Fig. 2 Kaplan-Meier Analysis of patients undergoing interval cytoreduction after NACT. Median time to progression was compared between patients who received perioperative blood transfusion (red line) versus those who did not (blue line). PFS $=7.6$ months for transfusion group; PFS $=9.44$ no transfusion group. Data were analyzed using the log-rank test 


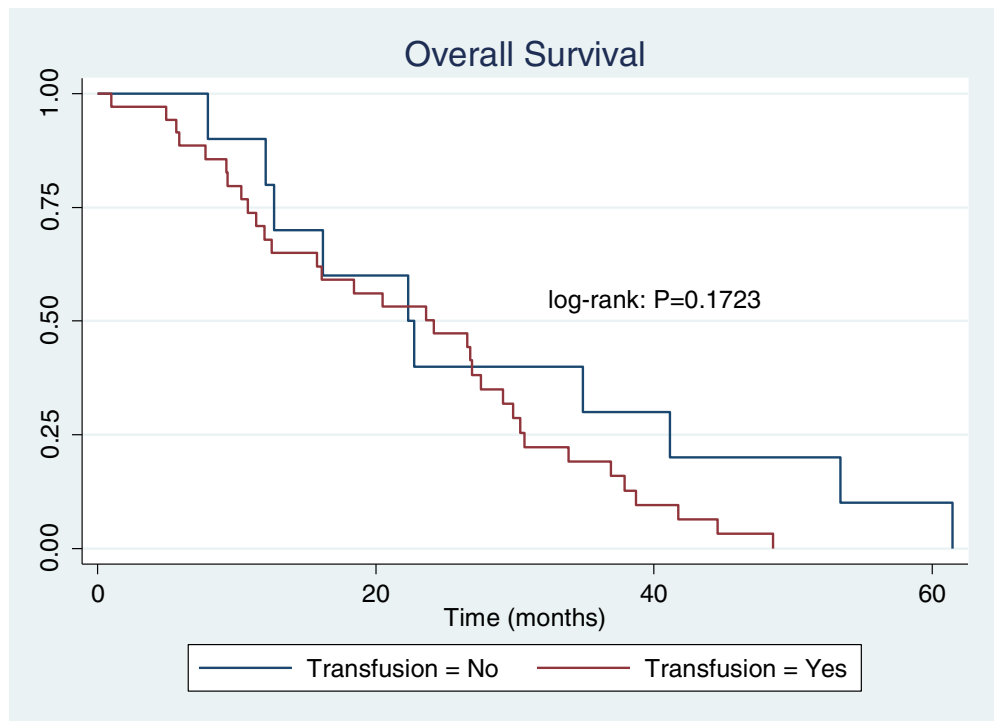

Fig. 3 Kaplan-Meier Analysis of patients undergoing interval cytoreduction after NACT

number of preoperative chemotherapy cycles and likelihood of exposure to perioperative blood transfusion. Nevertheless, in comparison to the patients included in the study of De Oliveira et al. we observed a lower preoperative hemoglobin level in our cohort $(10.5 \mathrm{~g} / \mathrm{dL}$ vs $11.2 \mathrm{~g} / \mathrm{dL}$ ) [8]. Congruently, we observed a higher rate of transfusion $(77 \%$ vs $56 \%$ ). We did not detect a difference in progression-free survival between women exposed to blood transfusion compared with women who were unexposed. Similarly, for the secondary outcome of overall survival, we did not observe a significant difference associated with exposure to blood transfusion. Two variables were significantly associated with exposure to transfusion: preoperative hemoglobin level and operative blood loss. While these are intuitive risk factors for transfusion, it is unlikely that operative blood loss can be reliably modified in patients undergoing cytoreductive surgery. As a result, correction of preoperative anemia may present an opportunity for future efforts geared towards reducing peri-operative blood transfusion.

Our data warrants contextualization with key articles from Vergote et al... and the CHORUS trial that investigated the non-inferiority of NACT with interval cytoreduction in ovarian cancer patients $[10,11]$. For our cohort, the overall median survival was 22.5 months. In comparison, Vergote et al.. observed a 30-month median overall survival in the NACT group. The CHORUS trial reported median overall survival of 24 months. It may be that the observed differences represent a relatively higher burden of disease in our patient population. Several lines of evidence support this: first, whereas Vergote et al.. observed stage IV disease in $23 \%$ of their patients, we observed stage IV disease in roughly $26 \%$ of our cohort. A similar rate of Stage IV disease was reported in the CHORUS trial (25\%). Second, Vergote et al observed a pretreatment CA125 of $\sim 1100$ units $/ \mathrm{mL}$. In contrast, we observed a pretreatment CA125 that was nearly three times greater $(\sim 2800$ units $/ \mathrm{mL})$. Though it was collected, the authors of the CHORUS trial did not publish the pretreatment CA125 levels in their study. In addition, Kessous et al recently published their experience from a retrospective cohort of North American women undergoing treatment for ovarian cancer and observed that women who received NACT had a roughly 3-fold higher CA125 level prior to treatment [12]. Collectively, these differences give support to the general practice patterns in the United States and North America that NACT is often reserved for patients with significant medical co-morbidities and/or a high burden of disease that would limit an optimal surgical effort. An important comparison between our cohort and the above mentioned trials is the apparent difference in the rates of blood transfusion between our U.S. cohort and the published European trials. While neither the Vergote study nor the CHORUS trial report specifically on blood product utilization, they do report grade 3 and 4 hemorrhage using Common Terminology Criteria for Adverse Events (CTCAE). Using these criteria, grade 3/4 hemorrhage would include all women undergoing blood transfusion of at least 2 units of packed red blood cells. The rate of grade 3 or 4 hemorrhage events among women undergoing NACT in these European trials ranged from 3 to $7 \%$. In stark contrast, $77 \%$ of women undergoing NACT in our cohort received a blood transfusion. While these two outcomes are not directly comparable, our data suggests that ovarian cancer patients 
who are treated with primary chemotherapy in North America represent a qualitatively different patient population that is at increased risk of exposure to allogeneic blood transfusion.

Our study has several shortcomings that limit its general applicability. Our design was retrospective and indications for transfusion are not standardized among providers. Moreover,

at our institution patients are often initiated on NACT by referring medical oncologists prior to a consultation with a gynecologic oncologist. This creates multiple opportunities for unmeasured variables to alter our results and conclusions. Moreover, the small number of subjects likely limited our ability to observe differences between groups that may exist. Future studies incorporating data from multiple institutions and/or collected prospectively with standardized procedures would address some of these limitations.

\section{Conclusion}

In conclusion, we found a high rate of perioperative allogeneic blood transfusion in women undergoing interval cytoreductive surgery for ovarian cancer after NACT. Larger and prospective trials will help further evaluate the relationship between blood transfusion and oncologic outcomes among women receiving NACT. We identified preoperative anemia and operative blood loss as risk factors for exposure to peri-operative transfusion. Future studies to evaluate the feasibility of correcting preoperative anemia while women are undergoing NACT may help reduce blood product utilization in this at-risk population.

\section{Additional file}

Additional file 1: "Deidentified raw clinical data". Raw clinical data, "Deidentified raw clinical data" includes all of the raw data used for analysis in the above study. (XLSX $17 \mathrm{~kb}$ )

\section{Abbreviations}

CTCAE: Common Terminology Criteria for Adverse Events;

NACT: Neoadjuvant chemotherapy

\section{Acknowledgements}

The authors appreciate the contributions of members of the Division of Gynecologic Oncology.

\section{Funding}

This study was funded by institutional support provided by the University of Wisconsin Department of Obstetrics and Gynecology.

\section{Availability of data and materials}

All raw clinical data is available in Additional file 1 Table S1.

\section{Authors' contributions}

KWM: conceived project, data acquisition, analysis and interpretation of data, manuscript,Preparation and approval, ES: analyzed data, provided statistical analysis, manuscript preparation and approval, BP: data acquisition, manuscript preparation and approval, EEM: conceived project, manuscript preparation and approval, JC: analysis and interpretation of data, manuscript preparation and approval, LB: conceived project, analysis and interpretation of data, manuscript preparation and approval. All authors read and approved the final manuscript.

\section{Ethics approval}

The study protocol was submitted to the UW-Madison Institutional Review Board and granted exemption status.

Consent for publication

Not applicable.

\section{Competing interests}

The author(s) declare(s) that they have no competing interests.

\section{Publisher's Note}

Springer Nature remains neutral with regard to jurisdictional claims in published maps and institutional affiliations.

\section{Author details}

'Division of Gynecologic Oncology, Department of Obstetrics and Gynecology, University of Wisconsin, 600 Highland Ave, Madison, WI 53792, USA.

${ }^{2}$ Department of Biostatistics and Medical Informatics, University of Wisconsin, 600 Highland Ave, Madison, WI 53792, USA. ${ }^{3}$ Department of Pathology and Laboratory Medicine, University of Wisconsin, 600 Highland Ave, Madison, WI 53792, USA. ${ }^{4}$ School of Medicine and Public Health, University of Wisconsin Hospital and Clinics, University of Wisconsin, 600 Highland Ave, Madison, WI 53792, USA. ${ }^{5}$ Penn Medicine/Lancaster General Health, LG Health Physicians Gynecologic Oncology Specialists, 2102 Harrisburg Pike, Lancaster, PA 17601, USA. 'University of Michigan, Division of Gynecologic Oncology, Department of Obstetrics and Gynecology, 1500 E. Medical Center Drive, Ann Arbor, Ml 48109-5276, USA.

Received: 26 September 2017 Accepted: 1 October 2018

Published online: 26 October 2018

References

1. Engoren $M$, Arslanian-Engoren C. Long-term survival in the intensive care unit after erythrocyte blood transfusion. Am J Crit Care. 2009 Mar;18(2):124-31.

2. Malone DL, Dunne J, Tracy JK, Putnam AT, Scalea TM, Napolitano LM. Blood transfusion, independent of shock severity, is associated with worse outcome in trauma. J Trauma. 2003 May;54(5):898-905.

3. Amato A, Pescatori M. Perioperative blood transfusions for the recurrence of colorectal cancer. Cochrane Database Syst Rev. 2006;1.

4. Beynon J, Davies PW, Billings PJ, Channer JL, Protheroe D, Umpleby HC, Mortensen NJ, Williamson RC. Perioperative blood transfusion increases the risk of recurrence in colorectal cancer. Dis Colon Rectum. 1989 Nov;32(11): 975-9.

5. Burrows $L$, Tartter $P$, Aufses $A$. Increased recurrence rates in perioperatively transfused colorectal malignancy patients. Cancer Detect Prev. 1987;10(5-6): $361-9$.

6. Nadeem R, Turkman B, Cha M. Impact of Perioperative Blood Transfusion on Survival Among Women with Breast Cancer. Am J Thera. 2017 May;16.

7. Abel EJ, Linder BJ, Bauman TM, Bauer RM, Thompson RH, Thapa P, Devon ON, Tarrell RF, Frank I, Jarrard DF, Downs TM, Boorjian SA. Perioperative blood transfusion and radical cystectomy: does timing of transfusion affect bladder cancer mortality? Eur Urol. 2014 Dec;66(6):1139-47.

8. De Oliveira GS Jr, Schink JC, Buoy C, Ahmad S, Fitzgerald PC, McCarthy RJ. The association between allogeneic perioperative blood transfusion on tumour recurrence and survival in patients with advanced ovarian cancer. Transfus Med 2012 Apr:22(2):97-103.

9. Abu-Rustum NR, Richard S, Wilton A, Lev G, Sonoda Y, Hensley ML, Gemignani M, Barakat RR, Chi DS. Transfusion utilization during adnexal or peritoneal cancer surgery: effects on symptomatic venous thromboembolism and survival. Gynecol Oncol. 2005 Nov;99(2):320-6.

10. Vergote I, Tropé CG, Amant F, Kristensen GB, Ehlen T, Johnson N, Verheijen RH,van der Burg ME, Lacave AJ, Panici PB, Kenter GG, Casado A, Mendiola C, Coens C, Verleye L, Stuart GC, Pecorelli S, Reed NS; European Organization for Research and Treatment of Cancer-Gynaecological Cancer Group.; NCIC Clinical Trials Group. Neoadjuvant chemotherapy or primary surgery in stage IIIC or IV ovarian cancer. N Engl J Med 2010;363(10):943-953.

11. Kehoe S, Hook J, Nankivell M, Jayson GC, Kitchener H, Lopes T, Luesley D, Perren T, Bannoo S, Mascarenhas M, Dobbs S, Essapen S, Twigg J, Herod J, 
McCluggage G, Parmar M, Swart AM. Primary chemotherapy versus primary surgery for newly diagnosed advanced ovarian cancer (CHORUS): an openlabel, randomised, controlled, non-inferiority trial. Lancet. 2015 Jul 18; 386(9990):249-57.

12. Kessous R, Laskov I, Abitbol J, Bitharas J, Yasmeen A, Salvador S, Lau S, Gotlieb WH. Clinical outcome of neoadjuvant chemotherapy for advanced ovarian cancer. Gynecol Oncol. 2017 Mar;144(3):474-9.

Ready to submit your research? Choose BMC and benefit from:

- fast, convenient online submission

- thorough peer review by experienced researchers in your field

- rapid publication on acceptance

- support for research data, including large and complex data types

- gold Open Access which fosters wider collaboration and increased citations

- maximum visibility for your research: over $100 \mathrm{M}$ website views per year

At $B M C$, research is always in progress.

Learn more biomedcentral.com/submissions 